\title{
Effect of Mirror Therapy Combined with Lower Extremity Muscle Strength Exercise on Gait and Balance of Patients with Chronic Stroke
}

\author{
Myoung-Kwon Kim, PhD • Young-Jun Shin, MS • Eun-Hong Choi, MS
}

Dept. of Physical Therapy, College of Rehabilitation Sciences, Daegu University

Received: November 12, 2017 / Revised: November 27, 2017 / Accepted: December 31, 2017

(C) 2018 J Korean Soc Phys Med

\section{| Abstract |}

PURPOSE: The present study aims to determine the effect of lower extremity muscle strength exercise at the non-paralyzed side of patients of stroke using a mirror on gait and balance.

METHODS: Subjects were assigned randomly to a group of lower extremity exercise without using a mirror $(n=10)$, a group of lower extremity motion exercise using a mirror $(n=10)$, and a group of lower extremity muscle strength exercise using a mirror $(n=10)$. The exercise is added to a physiotherapy program conducted at the hospital and subjects conducted their designed lower extremity exercises 30 times a day ( 5 sets), five days per week for four weeks.

RESULTS: The study result showed that BBS(Berg balance scale $)(\mathrm{p}<.05)$ and TUG(timed up and go test $)(\mathrm{p}<.05)$ had a significant difference. In the comparison on gait ability, stride length, step length, step width and single support was a significant difference within two groups using a mirror

†Corresponding Author : Eun-Hong Choi silvered1@hanmail.net, http://orcid.org/0000-0002-4585-0733 This is an Open Access article distributed under the terms of the Creative Commons Attribution Non-Commercial License (http://creativecommons.org/licenses/by-nc/3.0) which permits unrestricted non-commercial use, distribution, and reproduction in any medium, provided the original work is properly cited. before and after the intervention $(\mathrm{p}<.05)$.

CONCLUSION: Conclusively, low extremity motion exercise using a mirror and low extremity muscle strength exercise using a mirror conducted along with general physiotherapy exercises had a positive effect on functions of lower extremity in patients with stroke and the recovery of paralyzed side thereby incurring a significant difference in balance and gait abilities.

Key Words: Gait, Muscle strength, Stroke

\section{Introduction}

In stroke, the oxygen supply to the brain cells is blocked, which results in brain cell necrosis (Kolb and Gibb, 2007). Most survivors have decreased motor ability, and most patients do not fully recover (Cramer and Bastings, 2000). The most common motor disorder shown in patients is uncontrolled paretic movement (Hendricks et al., 2002). Paresis leads to the disuse of muscles, a secondary change in muscles and nerves. Chronic disuse causes muscle contracture and the atrophy of the motor cortex, thereby worsening the paresis (Cracies, 2005).

In particular, motor function paralysis of the lower limbs adversely affects balance and walking ability, thereby 
increasing the risk of falling (Liepert et al., 2000), 60\% of such patients with stroke have low walking speed and endurance (Hesse, 2008).

Post-stroke physical therapy mostly involves direct physical training using active and repetitive movements focusing on the paralyzed limbs as follows: exercise therapy (including pre-walking functional tasks such as movement activities and weight shift in sitting or standing position) (Ryerson and Levit, 1997), muscle strength and functional recovery using functional electric stimulation therapy (Sukanta et al., 2011), treadmill walking training (Talia et al., 2007), underwater treadmill training using a resistance machine (Jung and Lee, 2010), and lower extremity weight training using a circuit-group exercise program (Coralie and Susan, 2011). Concentrated exercise time is more effective in recovery motor function (Lee and Choi, 2016). However, if the paralyzed limbs are severely limited in their activities, the patients with stroke may be repulsed by a physical approach that focuses on functional recovery of the paralyzed limbs (Blanton and Wolf, 1999), thereby reducing the therapeutic effect.

Thus, treatment methods using the non-paretic side have been magnified to strengthen the weakened muscle strength on the paretic side. A study of normal subjects reported that wrist tendon training increased muscle activity in the contralateral wrist tendons (Lee et al., 2009) and exercise on the flexor of the elbow joint improved the activity of the flexor with the same function on the contralateral side (Carroll et al., 2006). The ultimate goal of treating patients with stroke is to change the paralyzed function with neuroplasticity by stimulating the central nerve to reduce abnormal parts of the posture and muscle tension, thereby increasing recovery into normal posture and movement and creating more efficient movement (Johansson, 2006). Out of all the methods of stimulating neuroplasticity, the activation method using "action-observation" activities is a cognitive training method used for motor skill improvement and learning both for patients with motor disorders and normal people (Rizzolatti et al., 2001). Thus, the increased cortex excitability of the premotor area and inferior parietal lobe shows that visual feedback training with "action-observation" is involved in motor learning (Zentgraf et al., 2005). Action observation training is effective in upper extremity function in stroke patients with moderate disability (Kim and Bang, 2016).

Mirror therapy training, a visual feedback training method, is based on imagining the non-paretic side projected on a mirror as the paretic side, and it is a known effective task-oriented therapy for patients with stroke (You et al., 2005). Related studies have reported that it has led to cerebral cortex restructuring and has promoted visual feedback and motor cortex activity (Bhasin et al., 2012). These studies focus on visual stimulation compared to paretic sensory motor training therapy (Holm et al., 2012).

Thus, many studies have investigated mirror therapy, a visual feedback method, to improve the functional condition of patients with stroke. Most focus on promoting visual stimulation using repeated upper and lower limb motions, and few studies have sought to evaluate the balance and gait of subjects according to the intensity by adding muscle strength exercise. Therefore, we compared existing mirror therapy with mirror therapy combined with muscle strength exercise using sandbags in this study to investigate the effects on subjects' balance and walking ability.

\section{METHODS}

\section{Subjects}

Among the patients diagnosed with stroke and hospitalized at M Hospital in Daegu since December 2016, 30 patients corresponding with the selection criteria below were selected. The subjects signed a voluntary participation agreement after being informed of the study's purpose and 
method. The enrollment criteria applied were as follows: 1) patients were diagnosed as having hemiplegia for at least six months by brain computed tomography (CT) or magnetic resonance imaging (MRI); 2) patients with stroke were at Brunnstrom stage $1-4 ; 3$ ) patients with stroke were able to walk. 4) patients with stroke had a 24 mini mental state examination-Korean (MMSE-K) score or greater, indicating no cognitive impairment; 5) patients with stroke had no visual problems. 6) patients with stroke had no limitations of joint contracture or range of motion.

According to the Declaration of Helsinki, information about the study was provided and the individuals gave written consent to participate. We described the purpose of the experiment to the patients with stroke admitted to M Hospital, Daegu and obtained IRB approval (1040621201702-HR011-02) from patients who agreed to participate in this study.

\section{Study protocol}

We conducted preliminary tests on all subjects prior to therapeutic intervention, and we classified subjects as follows: non-mirror lower extremity motion exercise group (control group), mirror lower extremity motion exercise group (experimental group I), and mirror lower extremity muscle strength exercise group (experimental group II). For randomization, sealed envelopes were prepared in advance and marked inside with $\mathrm{A}, \mathrm{B}$ or $\mathrm{C}$ representing experimental groups I, II, and control group, respectively. 30 subjects were divided into 10 groups for each group. This randomization was performed by a third party unaware of the nature of the study. Subject characteristics and all outcome measures obtained before and after treatment were assessed by Physical therapist, who was blinded to treatment allocations. Intervention was performed in a closed room by Physical therapist, who was not involved in subject assessment. Physical therapist was instructed not to communicate with subjects about study goals or treatments.

The subjects were provided with existing hospital treatment (central nervous system development therapy, occupational therapy, etc.) and the following experimental intervention. These interventions were conducted in five sets (30 times/set) five times each week for four weeks to provide the same amount of intervention to the subjects' non-paretic lower extremity. A one-minute break was provided between set. After four weeks of study intervention, we conducted a post test on all subjects. The progress and evaluation of the experiment was carried out by one researcher.

The intervention was conducted using a modified version of that described in the study of Sütbeyaz (2007). A mirror was mounted on a stand tilted toward the paretic side of the body to prevent the subject from viewing the paretic limb. For the experimental group I, II, the reflective surface was kept facing the non-paretic side. The exercises performed in a semi-seated position were : (1) hip-knee -ankle flexion, (2) knee extension with ankle dorsiflexion, and (3) knee flexion beyond $90^{\circ}$.

The control group was not provided with the motion of the non-paretic side, experimental group I was provided with visual information about the motion of the non-paretic side, and experimental group II was also provided with visual information of the non-paretic side, which was reflected in the mirror. Only experimental group II was performed with sand bags $(1 \mathrm{lb}, 2 \mathrm{lb}, 3 \mathrm{lb}, 4 \mathrm{lb}$, and 5 lb). The sand bag was selected by measuring the weight that each subject could lift 30 times before intervention. The weight was then increased by $1 \mathrm{lb}$ each week, and the existing weight was used when patients could not lift the sand bag 30 times.

\section{Measurement}

\section{1) Berg Balance Scale (BBS)}

The BBS is the most widely used and validated 
instrument for assessing balance performance in neurological conditions. It is composed of 14 items that require subjects to maintain positions of varying difficulty and perform specific tasks such as standing and sitting unsupported, transfers (sit to stand and stand to sit), turn to look over shoulders, pick up an object from the floor, turn $360^{\circ}$ and place alternate feet on a stool. Scoring is based on the subject's ability to perform the 14 tasks independently and/or meet certain time or distance requirements. Each item is scored on a 5-point ordinal scale ranging from 0 (unable to perform) to 4 (normal performance) so that the aggregate score ranges from 0 to 56. In a study of stroke patients, the test and retest reliability of the BBS was $\mathrm{r}=.98$ (Liston and Brouwer, 1996).

\section{2) Timed Up \& Go Test (TUG)}

TUG was used to measure the dynamic balance ability and gait ability of the subjects. Subjects were seated in a chair with armrests and then instructed to stand (using the armrests, if desired) and walk as quickly and as safely as possible for a distance of 3 meters. Subjects then turned around, returned to the chair, and sat down. The time from the point at which their spine left the back of the chair until they returned to that same position was recorded using a stopwatch. Each subject completed the TUG test three times with $30 \mathrm{~s}$ break between each time, and the average value was calculated. High interrater $(\mathrm{ICC}=.99)$ and interrater $(\mathrm{ICC}=.99)$ reliability have been demonstrated using this measure.

\section{3) Gait analysis}

The assessment was performed using the GAITRite portable walkway system ('Platinum model, CIR Systems Inc., Clifton, NJ, USA), which records the location and timing of each footfall during ambulation. The GaitRite system is an electronic walkway utilized to measure the temporal and spatial parameters of gait. The subjects walked at their preferred speed. Each subjects completed enough passes to allow for at least 18 footfalls to be analyzed (2-4 passes). The correlation coefficient between all gait measurements with comfortable walking speed was $\mathrm{r}=.92$ (Van Uden and Besser, 2004).

\section{Statistical Analysis}

Statistical analysis was performed using SPSS (SPSS Inc. Released 2009. PASW Statistics for Windows, Version 18.0 Chicago: SPSS Inc.). Subject general characteristics were analyzed using descriptive statistics and results are reported as means and standard deviations. The Shapiro- Wilk test was used to determine distribution normalities, and the paired t-test to compare the effects of interventions. One-way ANOVA was used for the group analysis, and the post-hoc LSD (least significant difference) test corrected for multiple comparisons. Null hypotheses of no difference were rejected if $\mathrm{p}$-values were less than .05 .

\section{RESULTS}

A summary of clinical and demographic features of the 30 study subjects in Table 1. The table also shows no significant intergroup differences were observed between baseline characteristics ( $>.05)($ Table 1).

Subjects in experimental group I and II showed significant increments compared to the control group in BBS $(\mathrm{p}<.05)$.

Subjects in experimental group I and II showed significant increments compared to the control group in TUG $(\mathrm{p}<.05)$.

Subjects in experimental group II showed significant increments compared to the control group in the stride length $(\mathrm{p}<.05)$. Subjects in experimental group I and II showed significant increments compared to the control group in the step length, step width $(\mathrm{p}<.05)$, experimental 
Table 1. General and Medical Characteristics of the Study Subjects

\begin{tabular}{|c|c|c|c|c|c|}
\hline Parameter & $\begin{array}{l}\text { Control group } \\
\quad(\mathrm{n}=10)\end{array}$ & $\begin{array}{l}\text { Experiment group I } \\
\qquad(\mathrm{n}=10)\end{array}$ & $\begin{array}{l}\text { Experiment group I } \\
\qquad(\mathrm{n}=10)\end{array}$ & $\mathrm{F}$ & $\mathrm{p}$ \\
\hline \multicolumn{6}{|l|}{ Gender } \\
\hline male & 6 & 3 & 4 & & \\
\hline female & 4 & 7 & 6 & & \\
\hline \multicolumn{6}{|l|}{ Type of stroke } \\
\hline hemorrhage & 4 & 4 & 9 & & \\
\hline infarction & 6 & 6 & 1 & & \\
\hline \multicolumn{6}{|l|}{ Paretic side } \\
\hline right & 6 & 2 & 5 & & \\
\hline left & 4 & 8 & 5 & & \\
\hline Age (year) & $62.1 \pm 9.52$ & $69.6 \pm 12.34$ & $72.3 \pm 11.35$ & 2.25 & .12 \\
\hline High $(\mathrm{cm})$ & $167.76 \pm 7.15$ & $160.67 \pm 7.01$ & $159.43 \pm 11.59$ & 2.58 & .09 \\
\hline Weight $(\mathrm{kg})$ & $65.67 \pm 16.24$ & $61.12 \pm 11.72$ & $56.48 \pm 8.62$ & 1.33 & .28 \\
\hline Brunnstrom stage & $3.1 \pm .73$ & $3.3 \pm .48$ & $3.0 \pm .66$ & .57 & .57 \\
\hline 2 stage & 2 & 0 & 2 & & \\
\hline 3 stage & 5 & 7 & 6 & & \\
\hline 4 stage & 3 & 3 & 2 & & \\
\hline MMSE-K & $25.1 \pm 1.20$ & $25.6 \pm 2.46$ & $26.4 \pm 1.65$ & 1.27 & .30 \\
\hline Stroke duration (m) & $29.1 \pm 25.03$ & $31.9 \pm 22.82$ & $30.6 \pm 22.29$ & .36 & .97 \\
\hline
\end{tabular}

MMSE-K: Mini Mental State Examination-Korean version

Mean \pm SD : Mean \pm Standard deviation

group I showed significant increments compared to the control group in the single support $(\mathrm{p}<.05)$ (Table 2$)$.

\section{DISCUSSION}

In this study, we compared existing mirror therapy that provides visual information about the non-paretic lower limb movement of patients with chronic stroke with mirror therapy combined with lower extremity muscle strength exercise using sand bags to determine the more effective method in terms of functional recovery.

The intervention method involved knee extension and bending by maintaining subjects' ankle dorsal flexion, thus stimulating the proprioception of the non-paretic side. The subjects repeated five sets 30 times to promote low intensity knee muscle activity of the non-paretic side. Moreover, the movement of the non-paretic side reflected in the mirror was provided as symmetric visual information in both experimental groups. The subjects performed imagery training on the paretic side (non-paretic exercise using mirror) to stimulate their cerebral cortex and thus influence their balance and walking ability. Improvement of BBS and TUG, Which is a balance evaluation, is considered to be a direct improvement of movement of the non-paretic side (eps. ankle dorsiflexion and knee extension) and an indirect effect of paralysis. Smorenburg et al. (2013) confirmed that upper limb function was improved when 
Table 2. Change in characteristics in the three study groups

\begin{tabular}{|c|c|c|c|c|c|c|c|}
\hline & & $\mathrm{CG}(\mathrm{n}=10)$ & EG I $\quad(n=10)$ & EG II $(\mathrm{n}=10)$ & F & Post-hoc & $\mathrm{p}$ \\
\hline \multirow[t]{2}{*}{ BBS (score) } & Pre. & $36.70(6.48)$ & $37.10(4.86)$ & $34.3(4.88)$ & .77 & & \\
\hline & Post. & $38.40(6.43)^{*}$ & $44.50(3.57)^{*}$ & $44.20(6.86)^{*}$ & $3.51^{*}$ & $\begin{array}{l}\mathrm{EG} \text { I }>\mathrm{CG} \\
\mathrm{EGI}>\mathrm{CG}\end{array}$ & $\begin{array}{l}.03 * \\
.03 *\end{array}$ \\
\hline \multirow[t]{2}{*}{ TUG (sec.) } & Pre. & $25.89(8.39)$ & $24.70(11.40)$ & $26.62(11.67)$ & .08 & & \\
\hline & Post. & $27.12(8.06)$ & $17.86(5.98)^{*}$ & $18.42(10.78)^{*}$ & $3.73 *$ & $\begin{array}{l}\mathrm{EG} \text { I }>\mathrm{CG} \\
\mathrm{EGI}>\mathrm{CG}\end{array}$ & $\begin{array}{l}.02^{*} \\
.03^{*}\end{array}$ \\
\hline \multicolumn{8}{|l|}{ Gait variable } \\
\hline cadence $($ step $/ \mathrm{min})$ & Post. & $85.02(23.95)$ & 102.21 (11.94)* & $107.01\left(^{(29.72)^{*}}\right.$ & 2.51 & & \\
\hline \multirow[t]{2}{*}{ stride length $(\mathrm{cm})$} & Pre. & $62.7(16.72)$ & $65.29(21.28)$ & $63.32(14.02)$ & .06 & & \\
\hline & Post. & $61.83(21.20)$ & 79.8 (26.83)* & $90.85(15.70)^{*}$ & & $\mathrm{EG} \amalg>\mathrm{CG}$ & $.01^{*}$ \\
\hline \multirow[t]{2}{*}{ step length $(\mathrm{cm})$} & Pre. & $34.89(11.26)$ & $35.36(13.88)$ & $32.11(7.85)$ & .24 & & \\
\hline & Post. & $34.80(13.70)$ & $49.88(13.12)^{*}$ & $52.50(11.40)^{*}$ & $5.59^{*}$ & $\begin{array}{l}\mathrm{EGI}>\mathrm{CG} \\
\mathrm{EGI}>\mathrm{CG}\end{array}$ & $\begin{array}{l}.01^{*} \\
.01^{*}\end{array}$ \\
\hline \multirow[t]{2}{*}{ step width $(\mathrm{cm})$} & Pre. & $23.19(7.15)$ & $28.98(6.78)$ & $20.49(8.63)$ & 2.47 & & \\
\hline & Post. & $21.99(8.12)$ & $31.62(6.23)^{*}$ & $29.80(10.69)^{*}$ & $8.20^{*}$ & $\begin{array}{l}\mathrm{EG} \mathrm{I}>\mathrm{CG} \\
\mathrm{EGI}>\mathrm{CG}\end{array}$ & $\begin{array}{l}.00^{*} \\
.00^{*}\end{array}$ \\
\hline \multirow[t]{2}{*}{$\begin{array}{c}\text { single } \\
\text { support }(\% \mathrm{GC})\end{array}$} & Pre. & $23.19(7.15)$ & $28.98(6.78)$ & 20.49 (8.63) & 3.29 & & \\
\hline & Post. & $21.99(8.12)$ & $31.62(6.23)^{*}$ & $29.80(10.69)^{*}$ & $3.58^{*}$ & EG I $>C G$ & $.02 *$ \\
\hline \multirow[t]{2}{*}{ velocity $(\mathrm{cm} / \mathrm{sec})$} & Pre. & $41.92(15.63)$ & $51.91(22.86)$ & $37.07(19.76)$ & 1.48 & & \\
\hline & Post. & $45.81(17.18)$ & $68.34(34.83)^{*}$ & $69.57(31.26)^{*}$ & 2.84 & & \\
\hline
\end{tabular}

CG: control group, EG I : experimental group I, EG I : experimental group I ${ }^{*} \mathrm{p}<.05$

visual feedback exercises were applied in children with spastic cerebral palsy. They reported that visual feedback of the non-damaged upper limb affected the movement of the damaged upper limb, thereby improving its function. Sütbeyaz et al. (2007) showed that the Brunnstrom stage and FIM score were significantly increased compared to the general physical therapy group when the mirror therapy was applied to the dorsiflexion of the ankle in subacute stroke. The significant increase in the walking ability for both experimental groups demonstrates that the intervention method provided symmetric movement to subjects, thus improving the subjects' static and dynamic stability and walking ability (symmetric movement). The visual feedback of movement of one side in the mirror enables bilateral exercise training and helps improve brain function (Yavuzer et al., 2008). Sütbeyaz et al. (2007) identified that mirror therapy improves brain plasticity through visual feedback and visual stimuli regulate the primary motor cortex's excitability. They confirmed that Brunnstrom stage and functional independent measure scores were significantly increased when the ankle dorsal flexion through 30 min-five days-four weeks mirror therapy was 
applied to patients with subacute stroke compared to the non-mirror lower extremity motion exercise group who received general physical therapy. Based on these results, they reported that therapeutic intervention combined with mirror therapy and general physical therapy improved exercise recovery in stroke patients. Ji (2013) showed that walking functional factors were significantly increased in the mirror therapy group when mirror therapy was conducted on stroke patients five times each week for eight weeks. He reported that the cadence and speed were significantly increased in both the mirror therapy group and non-mirror therapy group. Ji and Kim (2015) determined that single support, step length, and stride length were significantly increased in the experimental group I, II when mirror therapy training and virtual therapy training were applied to the lower limbs of patients with subacute stroke five times a week for four weeks. They reported that mirror therapy improved the lower limb function of patients with stroke; there was significant increase in the standing and walking test or walking ability when comparing before and after intervention. These results indicate that symmetrical movement is important in walking. The control group did not learn symmetrical movement because the visual information was not provided. In this study, symmetrical visual feedback using a mirror improved balance ability and single support, step length, stride length and step width which positively affected the spatial aspect of gait. However, the four-week intervention period was too short to affect the cadence and walking speed, both of which are temporal aspects of subjects' gait. The continuous mirror therapy combined with hospital treatment will have a positive effect on the cadence and walking speed.

The limitations of this study were as follows: 1) it is difficult to generalize the results because there were only 30 subjects; 2) Most subjects had the onset of chronic stroke two or more years prior to the study, thereby making it difficult to observe significant neurological and physical changes. Muscle strength exercise using sandbags was carried out on the non-paretic lower limb to observe the effects of resistance exercise combined with mirror therapy. However, there were some subjects who were over 60 years old and had difficulty in muscle strength exercise. Thus, low-intensity muscle strength exercise was performed in some cases, which meant that it was insufficient to carry out a comparison according to muscle strength exercise. Therefore, follow-up mirror therapy studies should compare the therapeutic effects according to the stroke onset period and the effect of low-intensity and high-intensity muscle strength exercise to fully determine the functional effect.

\section{References}

Bhasin A, Srivastava P, Kumaran S, et al. Neural interface of mirror therapy in chronic stroke patients: a functional magnetic resonance imaging study. Neurolo India. 2012;60(6):570-6.

Blanton S, Wolf SL. An application of extremity constraint induced movement therapy in a patient with subacute stroke. PhysTher. 1999;79:847-53.

Carroll TJ, Herbert RD, Munn J, et al. Contralateral effects of unilateral strength training: evidence and possible mechanisms. J Applied Physio. 2006;101(5):1514-22.

Coralie E, Susan H. Circuit class therapy for improving mobility after stroke: systematic review. J Rehabil Med. 2011;43:565-71.

Cracies JM. Pathophysiology of spastic paralysis. I : paresis and soft tissue change. Muscle Nerve. 2005;31(5): 535-51.

Cramer SC, Bastings EP. Mapping clinically relevant plasticity after stroke. Neuropharmacol. 2000;39:842-51.

Hendricks HT, van Limbeek J, Geurts AC, et al. Motor recovery after stroke: a systematic review of the literature. Arch Phys Med Rehabil. 2002;83(11):1629-37. 
Hesse S. Treadmill training with partial body weight support after stroke: a review. NeuroRehabil. 2008;22:1-11.

Holm T, Maria B, Marco W, et al. Mirror therapy for patients with severe arm paresis after stroke: a randomized controlled trial. ClinRehabil. 2012;27(4):314-24.

Ji SG. The effect of task oriented mirror therapy on balance and walking in subacute stroke patients. University of DongShin. 2013.

Ji SG, Kim MK. The effects of mirror therapy on the gait of subacute stroke patients: a randomized controlled trial. ClinRehabil. 2015;29(4):348-54.

Johansson BB. Brain plasticity and stroke rehabilitation. Stroke. 2006;31:223-30.

Kim CH, Bang DH. Action observation training enhances upper extremity function in subacute stroke survivor with moderate impairment: a double-blind, randomized controlled pilot trial. J Korean SocPhys Med, 2016; 11(1):133-40.

Kolb B, Gibb R. Brain plasticity and recovery from early cortical injury. Develop Psychobio. 2007;49:107-18.

Lee JH, Choi JD. Effects of intensive neuro rehabilitation intervention on the motor function recovery and balance in stroke patients. J Korean SocPhys Med, 2016; 11(4):41-7.

Lee M, Gandevia SC, Caroll TJ. Unilateral strength training increases voluntary activation of the opposite untrained limb. ClinNeurophysio. 2009;120(4):802-8.

Liepert J, Bauder H, Wolfgang HR, et al. Treatment induced cortical reorganization after stroke in humans. Stroke. 2000;31:1210-6

Liston R, Brouwer B. Reliability and validity of measures obtained from stroke patients using the balance master. Arch Phys Med Rehabil. 1996;77(5):425-30.

Rizzolatti G, Fogassi L, Gallese V. Neurophysiological mechanisms underlying the understanding and imitation of action. Nat Rev NeuroSci. 2001;2:661-70.

Ryerson S, Levit K. Functional movement reduction: a complementary model for stroke rehabilitation. New York : Churchill Livingstone. 1997.

Smorenburg ARP, Ledebt A, Deconinck FJA. Practicing a matching movement with a mirror in individuals with spastic hemiplegia. Research InDevelpDisabili. 2013; 34:2507-13.

Sukanta KS, Chhanda S, Ratnesh K, et al. Functional electrical stimulation of dorsiflexor muscle: Effects on dorsiflexor strength, plantarflexor spasticity and motor recovery in stroke patients. NeuroRehabil. 2011;29: 393-400.

Sütbeyaz S, Yavuzer G, Sezer N, et al. Mirror therapy enhances lower extremity motor recovery and motor functioning after stroke. Arch Phys Med Rehabil. 2007;88:555-9.

Jung TY, Lee DK. The influence of applying additional weight to the affected leg on gait patterns during aquatic treadmill walking in people poststroke. Arch Phys Med Rehabil. 2010;91:129-36.

Talia H, Nir G, Leor G, et al. Six weeks of intensive treadmill training improves gait and quality of life in patients with Parkinson's disease: a pilot study. Arch Phys Med Rehabil. 2007;88:1154-58.

Van Uden C, Besser M. Test-retest reliability of temporal and spatial gait characteristics measures with an instrumented walk way system(GAITRite). BMC Musculoskeletal Disorders. 2004;5:13

Yavuzer G, Selles R, Sezer N, et al. Mirror therapy improves hand function in subacute stroke: a randomized controlled trial. Arch Phys Med Rehabil. 2008; 89(3):393-8.

You SH, Jang SH, Kim YH, et al. Virtual reality, induced cortical reorganization and associated locomotor recovery in chronic stroke. Stroke. 2005;36:1166-71.

Zentgraf K, Stark R, Reiser M, et al. Differential activation of pre-SMA and SMA proper during action observation: effects of instructions. Neuroimage. 2005;26:662-72. 